\title{
NAD reduction under alkaline hydrothermal conditions
}

\author{
DELFINA PATRÍCIA HENRIQUES PEREIRA, MA, \\ ANDREY DO NASCIMENTO VIEIRA, KARL \\ KLEINERMANNS, WILLIAM F MARTIN AND MARTINA \\ PREINER
}

Heinrich Heine University

Presenting Author: dph.pereira@campus.fct.unl.pt

In serpentinizing systems, iron-rich minerals react with water to produce molecular hydrogen, $\mathrm{H}_{2}$, in an exothermic reaction, resulting in an alkaline environment that possibly could have hosted the origin of life[1]. While the origin of the first metabolism on earth was dependent on specific surrounding chemical conditions which might have left their imprint within metabolism itself, life became more complex, self-replicating and ultimately differentiated itself from the surrounding environment enough to explore other ecosystems.

In modern microbes, hydrogen is still essential, participating actively in every metabolism as hydride, though not as $\mathrm{H}_{2}$ or $\mathrm{H}^{-}$, but in the form of electron carriers such as nicotinamide adenine dinucleotide (NAD). In serpentinizing systems, hydrides could be bound to the surface of minerals. Even though the transition from inorganic minerals to complex cofactors such as NAD is unclear, they must have co-existed at some point during the early stages of the origin of metabolism, as NAD is present in every living being on earth and in numerous of different metabolic pathways[2].

In this work we combined hydrothermal conditions found in serpentinizing systems with iron and other mineral bound hydrides to successfully reduce $\mathrm{NAD}^{+}$to NADH using $\mathrm{H}_{2}$, establishing an important step in the transition from abiotic to biotic chemistry.

1. Baross, J. A. \& Hoffman, S. E. (1985) Origins of life and evolution of the biosphere. 15, 327-345.

2. Fontecilla-Camps, J. C. (2019) Angewandte ChemieInt. Ed. 58, 42-48. 